\title{
The modifier of Min 2 (Mom2) locus: Embryonic lethality of a mutation in the Atp5al gene suggests a novel mechanism of polyp suppression
}

\author{
Amy A. Baran, ${ }^{1,4}$ Karen A. Silverman, ${ }^{1,4,6}$ Joseph Zeskand, ${ }^{1,7}$ Revati Koratkar, ${ }^{1}$ \\ Ashley Palmer, ${ }^{1,8}$ Kristen McCullen, ${ }^{2}$ Walter J. Curran Jr, ${ }^{1}$ Tina Bocker Edmonston, ${ }^{3}$ \\ Linda D. Siracusa, ${ }^{1,5}$ and Arthur M. Buchberg ${ }^{1,5,9}$ \\ ${ }^{1}$ Kimmel Cancer Center, Thomas Jefferson University, Jefferson Medical College, Philadelphia, Pennsylvania 19107, USA; \\ ${ }^{2}$ Department of Obstetrics and Gynecology, Thomas Jefferson University, Jefferson Medical College, Philadelphia, Pennsylvania \\ 19107, USA; ${ }^{3}$ Department of Pathology, Anatomy, and Cell Biology, Thomas Jefferson University, Jefferson Medical College, \\ Philadelphia, Pennsylvania 19107, USA
}

Inactivation of the $A P C$ gene is considered the initiating event in human colorectal cancer. Modifier genes that influence the penetrance of mutations in tumor-suppressor genes hold great potential for preventing the development of cancer. The mechanism by which modifier genes alter adenoma incidence can be readily studied in

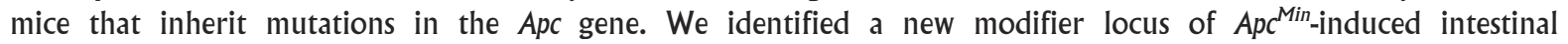
tumorigenesis called Modifier of $\underline{\operatorname{Min}} \underline{2}$ (Mom2). The polyp-resistant $M o m 2^{R}$ phenotype resulted from a spontaneous mutation and linkage analysis localized Mom2 to distal chromosome 18. To obtain recombinant chromosomes for use in refining the Mom2 interval, we generated congenic DBA.B6 $A p c^{\mathrm{Min} /+}$, Mom2 ${ }^{R /+}$ mice. An intercross revealed that $M o m 2^{R}$ encodes a recessive embryonic lethal mutation. We devised an exclusion strategy for mapping the Mom2 locus using embryonic lethality as a method of selection. Expression and sequence analyses of candidate genes identified a duplication of four nucleotides within exon 3 of the $\alpha$ subunit of the ATP synthase (Atp5aI) gene. Tumor analyses revealed a novel mechanism of polyp suppression by $M o m 2^{R}$ in Min mice. Furthermore, we show that more adenomas progress to carcinomas in Min mice that carry the Mom $2^{R}$ mutation. The absence of loss of heterozygosity (LOH) at the Apc locus, combined with the tendency of adenomas to progress to carcinomas, indicates that the sequence of events leading to tumors in $\mathrm{Apc}^{\mathrm{Min} /+} \mathrm{Mom} 2^{R /+}$ mice is consistent with the features of human tumor initiation and progression.

[Supplemental material is available online at www.genome.org.]

Colorectal cancer is one of the leading causes of cancer deaths in the United States (www.cancer.org). The dysregulation of normal colonic epithelium leads to the formation of adenomas, which are considered a prerequisite to progression to carcinoma (Fodde et al. 2003). This multistep process involves interactions between the genome and the gut environment, leading to mutations and epigenetic changes in oncogenes and/or tumor suppressor genes (Kinzler and Vogelstein 1996; Ilyas et al. 1999; Gregorieff and Clevers 2005). However, the variation in penetrance of hereditary forms of cancer has emphasized the impact of tumormodifier genes that can influence individual susceptibility to cancer by either enhancing or suppressing the initiation, growth, and/or progression of tumor cells. Due to environmental and genetic heterogeneity in the human population, it has been difficult to identify tumor modifier loci in humans. Therefore, com-

\footnotetext{
${ }^{4}$ Co-first authors.

${ }^{5}$ Co-senior authors.

Present addresses: ${ }^{6}$ The Children's Hospital of Philadelphia, Philadelphia, PA 19104, USA; ${ }^{7}$ Alexion Pharmaceuticals, Cheshire, CT 06410, USA; ${ }^{8}$ Hematology Department, Brigham and Women's Hospital, Boston, MA 02115, USA.

${ }^{9}$ Corresponding author.

E-mail buchberg@mail.jci.tju.edu; fax (215) 923-4153.

Article published online before print. Article and publication date are at http:// www.genome.org/cgi/doi/10.1101/gr.6089707.
}

plex trait analysis in experimental mouse crosses is a powerful approach to genetically dissect multigenic diseases (Moore and Nagle 2000; Threadgill et al. 2002; Siracusa et al. 2004).

The mapping, identification, and characterization of genes influencing tumor susceptibility has been facilitated by the use of mammalian models (Mao and Balmain 2003). Inbred strains of mice that differ in their susceptibility to various types of solid tumors and leukemias have been instrumental in uncovering loci that affect tumor risk (Dragani 2003; Mao and Balmain 2003). Tumor susceptibility genes may act cell autonomously within the tumor lineage, or may act in a non-cell autonomous fashion within the microenvironment leading to tumor formation (Demant 2003). Genomic differences among inbred strains of mice are being exploited to limit the regions containing the causative allelic variants and ultimately identify the genes responsible (Siracusa et al. 2004).

Modifier genes affect the phenotype caused by a mutation in another gene. A classic example of such a system with respect to tumorigenesis involves loci called the Modifiers of Min (Mom), which influence the intestinal tumor phenotype of Min mice carrying a mutation in the adenomatous polyposis coli gene $\left(A p C^{M i n}\right)$ (Dietrich et al. 1993). To date, four Mom loci have been identified (Mom1, Mom2, Mom3, and Mom6) (Dietrich et al. 1993; Cormier et al. 2000; Silverman et al. 2002; Haines et al. 2005), but only one gene has, as yet, been proven to be responsible for 
altering the Mom phenotype otherwise dictated by a mutation in the Apc gene (MacPhee et al. 1995; Cormier et al. 1997).

Our laboratory identified the Mom2 locus in hybrid offspring derived from a cross involving DBA/2J (DBA) and C57BL/ 6J (B6) $\mathrm{Apc}^{\mathrm{Min} /+}$ mice (Silverman et al. 2002). We initially localized Mom2 to a 14-cM region on distal chromosome 18, between the D18Mit186 and D18Mit213 markers. Inheritance patterns of the Mom2 phenotype suggested that the resistant Mom2 allele $\left(M o m 2^{R}\right)$ arose from a spontaneous mutation in a B6 $A p c^{\mathrm{Min} /+}$ progenitor. On both inbred strain backgrounds, one $M o m 2^{R}$ allele decreases small intestinal polyp number and colon polyp incidence by $\sim 90 \%$ (Silverman et al. 2002); thus, $M o m 2^{R}$ has significantly greater effects on polyp multiplicity than $M o m 1^{R}$, which, when present in one copy, decreases small intestinal polyp number and size by $\sim 50 \%$ (Cormier et al. 1997; Silverman et al. 2002).

The presence of the Mom 1 locus, in addition to other unlinked modifiers of intestinal polyp formation in the mouse genome, indicated the necessity to control genetic background for further studies of the Mom 2 locus. Therefore, we generated congenic mice carrying the $M o m 2^{R}$ allele on both the DBA and B6 inbred strain backgrounds (Silverman et al. 2003). The Mom2 locus was limited to $<10 \mathrm{cM}$ by genotyping progeny and comparing small intestinal polyp multiplicity with the distribution of recombinant breakpoints (Silverman et al. 2003).

We now report that intercrosses of DBA.B6 Mom $2^{R /+}$ animals produced no offspring homozygous for the resistant $M o m 2^{R}$ allele. To facilitate the genetic dissection of Mom2, we established crosses between DBA.B6 Mom2 $2^{R /+}$ animals and Mus musculus castaneus (CAST) mice. The increase in polymorphic markers, coupled with making use of the Mom $2^{R}$ homozygous lethal phenotype, provided an exclusion mapping strategy that refined the Mom2 interval to $<1 \mathrm{Mb}$. Our finding of a duplication that disrupts the Atp5a1 gene, a gene required for oxidative metabolism, provided testable hypotheses for both the modifier effect on $A p c^{M i n}$-induced tumorigenesis and the phenotype of recessive embryonic lethality.

\section{Results}

Intercrosses of congenic DBA.B6 Mom2 $2^{R /+}$ mice fail to generate homozygous $M o m 2^{R}$ progeny

To maintain the $M o m 2^{R}$ mutation, as well as to obtain recombinant chromosomes for use in the refinement of the Mom2 locus, we generated congenic animals carrying the C57BL/6J (B6) $M o m 2^{R}$ allele on the DBA/2J (DBA) genetic background by sequential backcrosses (Silverman et al. 2003). Offspring were genotyped for the $A p c^{M i n}$ mutation and genotyped for the Mom2 locus using the Mom2 flanking markers D18Mit80 and D18Mit213 (Silverman et al. 2003). Progeny were selected that carried the resistant Mom2 allele $\left(M o m 2^{R}\right)$, but did not carry the $A p c^{M i n}$ mutation. DBA.B6 Mom2 $2^{R /+}$ animals from the N4-N5 backcross generations were intercrossed to generate animals homozygous for the resistant Mom $2^{R}$ allele. Surprisingly, our intercross resulted in $36 \mathrm{~F}_{2} \mathrm{Mom}^{R /+}$ heterozygotes and $25 \mathrm{~F}_{2}$ wild-type $M o m 2^{+/+}$progeny, with no $\mathrm{F}_{2}$ animals homozygous for the $M o m 2^{R}$ allele. $\chi^{2}$ analysis indicated that the expected Mendelian distribution of 1:2:1 was significantly different $(P<0.001)$ from the observed distribution of $F_{2}$ animals obtained from our $M o m 2^{R}$ intercross (1.4:1). In addition, the observed 1.4:1 $\left(\mathrm{Mom2}^{R /+}: \mathrm{Mom}^{+/+}\right)$ratio was not significantly different $(P=0.2)$ from a ratio of $2: 1\left(\mathrm{Mom}^{R /+}: \mathrm{Mom}^{+/+}\right)$, suggesting that the $M o m 2^{R}$ allele is a recessive embryonic lethal mutation. Additional experiments have confirmed that homozygous $M o m 2^{R}$ mice are never born (see below).

\section{The $M o m 2^{R}$ locus encodes a recessive embryonic lethal} mutation

We tested the hypothesis that the mutant $M o m 2^{R}$ allele may impair the normal function of either oocytes or sperm by determining whether $M o m 2^{R}$ could be equally inherited from a heterozygous Mom $2^{R /+}$ mother or a heterozygous $M o m 2^{R /+}$ father. Table 1 shows the crosses, number of mating cages, and genotypes of the resulting progeny. In two of the four backcrosses, offspring could inherit a $M o m 2^{R}$ allele from their heterozygous mother, whereas in the remaining two backcrosses, offspring could inherit a $M o m 2^{R}$ allele from their heterozygous father. Analysis of the distribution of $\mathrm{Mom} 2^{R /+}$ versus $\mathrm{Mom}^{+/+}$offspring by the $\chi^{2}$ test revealed no significant differences in inheritance patterns between the mutant $M o m 2^{R}$ and wild-type $M o m 2^{+}$loci (Table 1). Therefore, the function of oocytes and sperm do not appear to be impaired by the presence of the $M o m 2^{R}$ mutation. The data suggest that the death of $M o m 2^{R / R}$ embryos occurs sometime after fertilization, but before birth.

To investigate the developmental stage of embryonic lethality, timed pregnancies from intercrosses of DBA.B6 Mom $2^{R /+}$ mice were established. A total of 41 embryos, which includes embryonic tissue from six resorption sites, were obtained from six females at 12.5 d post coitus (dpc). Genomic DNA from each embryo was genotyped for the Mom2 flanking markers, D18Mit80 and D18Mit213, to distinguish the presence of the B6 Mom2 $2^{R}$ locus from the wild-type DBA Mom2 ${ }^{+}$locus (Silverman et al. 2003). Ten embryos were homozygous for the wild-type DBA allele at both loci, 24 embryos were heterozygous for the B6 and DBA alleles at both loci, and seven embryos were single recombinants (three embryos were D/B at the D18Mit80 locus and D/D at the D18Mit213 locus; two embryos were D/D at the D18Mit80 locus and D/B at the D18Mit213 locus; and two embryos were D/B at the D18Mit80 locus and B/B at the D18Mit213 locus). None of the 41 embryos were homozygous for B6 alleles at both the D18Mit80 and D18Mit213 loci, demonstrating that Mom2 $2^{R / R}$ embryos die before $12.5 \mathrm{dpc}$.

\section{Refining the localization of Mom2 by an exclusion mapping strategy}

The proof of embryonic lethality coupled with the ability to detect recombinants in the Mom2 region provided a strategy to

Table 1. The $M o m 2^{R}$ allele can be transmitted to offspring from both female and male parents

\begin{tabular}{|c|c|c|c|c|c|}
\hline Cross $^{a}$ & $\begin{array}{l}\text { No. of } \\
\text { mating } \\
\text { cages }\end{array}$ & Mom2 $^{+/+}$ & $\operatorname{Mom} 2^{R /+}$ & $x^{2}$ & $P$ value \\
\hline $\begin{array}{l}\text { DBA.B6 Mom2 } 2^{R /+} \times \text { B6 } \\
\quad \text { Apc }^{\operatorname{Min} /+}\end{array}$ & 6 & 41 & 31 & 1.4 & $P>0.05$ \\
\hline $\begin{array}{c}\text { DBA.B6 } \mathrm{Apc}^{\mathrm{Min} /+} \\
\text { Mom } 2^{R /+} \times \mathrm{DBA}^{\prime} \\
\text { DBA } \times \text { DBA.B6 }\end{array}$ & 6 & 31 & 27 & 0.3 & $P>0.05$ \\
\hline $\begin{array}{c}\text { Mom2 } 2^{R /+} \\
\text { DBA } \times \text { DBA.B6 }\end{array}$ & 5 & 50 & 53 & 0.1 & $P>0.05$ \\
\hline $\mathrm{Apc}^{\mathrm{Min} /+}, \mathrm{Mom}^{\mathrm{R} /+}$ & 10 & 88 & 93 & 0.1 & $P>0.05$ \\
\hline
\end{tabular}

The D18Mit80 and D18Mit213 markers were used to distinguish the presence of the B6 Mom2 $2^{R}$ locus from the wild-type DBA Mom2 $2^{+}$locus (Silverman et al. 2003).

${ }^{a}$ For each cross, the female is listed first. 
further define the boundaries of the $M o m 2^{R}$ locus. To facilitate the genetic dissection and further refinement of the Mom2 interval, we initiated crosses with CAST/Ei (CAST) mice (Silver 1995). The CAST subspecies diverged from common laboratory strains by one to two million years, thus providing genetic diversity to increase the number of polymorphisms (Silver 1995). Six mating cages of CAST $\times$ DBA.B6 Mom $2^{R /+}$ animals from the N7-N8 backcross generations (Fig. 1A) produced $94 \mathrm{~F}_{1}$ offspring that were genotyped for the Mom 2 region. While all $\mathrm{F}_{1}$ offspring inherited a CAST allele at each marker, either a DBA allele $\left(\mathrm{Mom}^{+}\right)$or the B6 allele $\left(\mathrm{Mom} 2^{R}\right)$ could be inherited from the heterozygous DBA.B6 Mom $2^{R /+}$ congenic parent. Since the $M o m 2^{R}$ mutation arose on a $\mathrm{B} 6$ background, $\mathrm{F}_{1}$ progeny were selected that carried the B6 allele at both the proximal D18Mit186 and distal D18Mit213 markers. These [CAST $\times$ DBA.B6 Mom2 $\left.2^{R /+}\right]_{1}$ hybrid mice were intercrossed to generate $\mathrm{F}_{2}$ progeny that were genotyped for D18Mit186 and D18Mit213. Only $\mathrm{F}_{2}$ animals recombinant within the Mom2 interval were subjected to further screening (Fig. 1B).

We used an exclusion mapping technique for the Mom2 locus based on the lack of Mom $2^{R / R}$ homozygous liveborn progeny from the DBA.B6 Mom $2^{R /+}$ intercross. Since $M o m 2^{R}$ is a recessive embryonic lethal mutation, no animals homozygous for the B6 Mom $2^{R}$ allele should survive. Therefore, any marker within the Mom 2 region that was homozygous for the $\mathrm{B} 6$ allele would be excluded as being part of the Mom2 locus (Fig. 1B,C). Progeny from the $\left[\right.$ CAST $\times$ DBA.B6 Mom $\left.2^{R /+}\right] \mathrm{F}_{1}$ intercross were identified that were $\mathrm{B} / \mathrm{B}$ at either the proximal (D18Mit186) or distal (D18Mit213) markers, and were B/C or C/C at the other, indicating that a recombination occurred within the Mom2 region (Fig. 1B). Of $536 \mathrm{~F}_{2}$ offspring, 22 were informative recombinants. No $\mathrm{F}_{2}$ progeny were identified that were $\mathrm{B} / \mathrm{B}$ at both the D18Mit186 and D18Mit213 markers; 452 nonrecombinant $\mathrm{F}_{2}$ animals showed a distribution of 159: 293: 0 (C/C: B/C: B/B), with a 1: 1.8 ratio instead of a Mendelian 1:2:1 ratio $\left(\chi^{2}=129.4, P<0.0001\right)$, confirming the recessive embryonic lethality of the $M o m 2^{R}$ mutation.

To further dissect the Mom2 locus, the 22 recombinant $\mathrm{F}_{2}$ animals were genotyped for additional markers (Fig. 1C). The spontaneous mutation that created the $M o m 2^{R}$ allele did not appear to cause a gross deletion, inversion, or large alteration that affected genes in the region. All markers, with the exception of D18Mit47 and D18Mit106, were homozygous for B/B alleles in at least one mouse, thus excluding them from consideration (Fig. 1C). Analysis of recombination breakpoints indicates that the Mom2 locus must reside between the D18Kcc2 (within the St8sia5 [formerly known as Siat8e] gene) and D18Kcc10 (within the Slc14a2 gene) markers (Supplemental Table 1).

To further narrow the location of the Mom 2 gene, $\mathrm{F}_{2}$ progeny that were heterozygous for the Mom2 region were sequentially intercrossed. $\mathrm{F}_{3}$ offspring were identified that carried crossovers between the St8sia 5 and Slc14a2 genes. Intercrosses of these recombinant $\mathrm{F}_{3}$ progeny produced $64 \mathrm{~F}_{4}$ mice that were either pure CAST or mice that were heterozygous throughout the Mom2 region. No mice that were homozygous for B6 alleles in the Mom2 region were born, consistent with the recessive embryonic lethality of the $M o m 2^{R}$ mutation. These data demonstrated that the region distal to St8sia5 and proximal to D18KcC7 (within the 5430411 K18Rik gene) contained a recessive embryonic lethal mutation and excluded both the Slc14a1 and Slc14a2 genes as candidates (Supplemental Table 1). Based on Build 34 from the Ensembl database, the Mom2 interval is $\sim 800 \mathrm{~kb}$ in length and
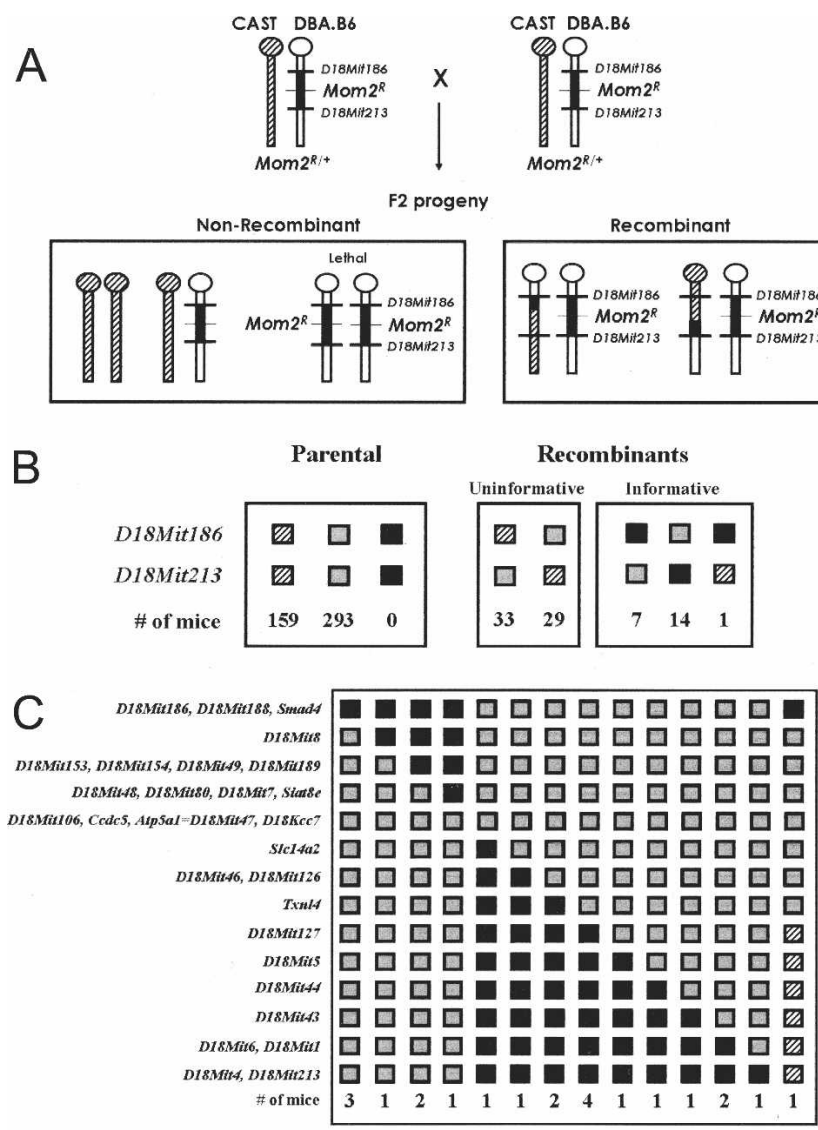

\begin{tabular}{|lll|}
\hline $\mathrm{DBA}$ & $\mathrm{B}$ B $\mathrm{CAST}$ \\
\hline
\end{tabular}

Figure 1. Exclusion mapping strategy to refine the Mom2 locus. $(A)$ Based on the observation that the Mom $2^{R}$ locus encodes a recessive embryonic lethal mutation, we devised a strategic intercross of (CAST $\times$ DBA.B6 Mom2 $\left.2^{R /+}\right) \mathrm{F}_{1}$ mice to limit the boundaries of the Mom2 locus. Since mice homozygous for the B6 Mom $2^{R}$ allele (B/B) should not survive, markers within the Mom2 region that were homozygous for B6 alleles would be excluded. DBA.B6 Mom $2^{R /+}$ animals from the N7-N8 generations were mated to CAST mice. DBA chromosomes are shown in white; the B6 Mom $2^{R}$ region is shown in black; CAST chromosomes are represented by diagonal stripes and heterozygotes are shown in gray. The possible $\mathrm{F}_{2}$ progeny are shown in black boxes; all offspring were genotyped for proximal (D18Mit186) and distal (D18Mit213) markers flanking Mom2 (Silverman et al. 2002, 2003). (B) The number of resulting $F_{2}$ progeny are shown below the boxes. Nonrecombinant $F_{2}$ progeny are in the black box on the left; representative recombinant progeny are in the boxes to the right. $\mathrm{F}_{2}$ offspring that were $\mathrm{B} / \mathrm{B}$ at either the proximal (D18Mit186) or distal (D18Mit213) marker and were B/C or C/C at the other, indicated the occurrence of a recombination within the Mom2 region. Nonrecombinant CAST DBA.B6 Mom $2^{R}$ animals were uninformative for linkage analysis. (C) Haplotype analysis of recombinant $F_{2}$ animals from the $\left[\right.$ CAST $\times$ DBA.B6 Mom $\left.2^{R /+}\right] F_{1}$ intercross. Mapped loci are listed on the left. Numbers below each column of boxes represent the number of $\mathrm{F}_{2}$ progeny that fall into each haplotype. $\mathrm{F}_{2}$ progeny were identified that were $B / B$ at either the proximal or distal marker, and were $B / C$ or $C / C$ at the other, indicating an informative recombinant within the Mom2 region; these 22 mice were genotyped by PCR for polymorphic markers within the Mom2 region. This analysis positioned Mom2 between the D18Mit7 locus and the Slc14a2 gene.

encodes six known genes, one novel gene, one pseudogene, and one predicted gene (www.ensembl.org/Mus musculus/October 2005). 
Expression analysis and sequencing of genes within the Mom2 region reveals a mutation in the Atp5al gene

Based on an early-acting recessive embryonic lethal mutation at the Mom2 locus, we hypothesized that the mutated gene would most likely represent a null allele. Therefore, we examined the expression levels of genes within the Mom2 interval by real-time PCR. Assays-on-Demand (ABI) provided tests for Atp5a1, Ccdc5, Loxhd1, Pstpip2, 8030462N17Rik, and St8sia5. Total RNA was isolated from the proximal and distal small intestine and colon of congenic DBA.B6 Mom $2^{R /+}$ mice along with control DBA and B6 mice. Of all the genes tested, only the Atp5a1 gene showed a significant decrease in mRNA levels compared with that predicted for a $\mathrm{DBA} \times \mathrm{B} 6 \mathrm{~F}_{1}$ hybrid (Fig. 2A).

Results of real-time PCR were consistent with the Atp5a1 gene being expressed solely from the DBA allele in the congenic DBA.B6 Mom $2^{R /+}$ mice. Therefore, we sequenced each exon of the Atp5a1 gene from genomic DNA of congenic DBA.B6 Mom $2^{R /+}$ and B6 Mom $2^{R /+}$ mice, along with control DBA and B6 mice (Supplemental Table 2). The results revealed a 4-bp duplication in the coding region (exon 3 ), which was present in mice carrying the $M o m 2^{R}$ allele and absent in $\mathrm{Mom}^{+/+}$controls (Fig. 2B). This duplication is predicted to cause a frameshift mutation, which would result in aberrant incorporation of 42 amino acids followed by a stop codon in exon 4 , downstream of the mutation site (Fig. 2C). If the transcript from the $M o m 2^{R}$ allele was equally stable as from the $\mathrm{Mom}^{+}$allele, the predicted mutant mRNA would be the same size as the wild-type mRNA, and was therefore not detectable by Northern blot analyses (data not shown). However, sequencing cDNA generated from $M o m 2^{R /+}$ intestines failed to identify any mutant Atp5a1 transcripts, suggesting that this allele does not generate a stable transcript (data not shown). In addition, sequencing of the flanking Ccdc5 and Pstpip2 genes showed no differences between $M o m 2^{R /+}$ mice and wild-type mice (Supplemental Tables 3, 4).

To further cement the relationship between the 4-bp duplication in the Atp5a1 gene and the $M o m 2^{R}$ phenotype, we sequenced the original B6 $A p c^{\mathrm{Min} /+}$ father who first transmitted the $M o m 2^{R}$ allele to his progeny (Silverman et al. 2002); results showed that he indeed carried the mutation. Sequencing of five $M o m 2^{R /+}$ mice, three from the real-time PCR studies, and the two $\mathrm{F}_{3}$ parents (see above), further confirmed the presence of the mutation in mice carrying the $M o m 2^{R}$ allele. No polymorphisms between the DBA and B6 strains in coding regions, untranslated regions, or splice junctions were found.

We designed a positive/negative PCR-based assay to detect the presence of the mutated Atp5a1 allele using a forward primer that incorporated the 4-bp duplication in its sequence (see Methods). The specificity of the primer ensured that it would only bind a genomic fragment that contains the mutant Atp5a1 allele. A PCR fragment of $147 \mathrm{bp}$ was detected if the Atp5a1 duplication was present, whereas no fragment was produced from the wildtype allele. Further studies compared the number of polyps in $A p c^{\mathrm{Min} /+}$ mice carrying the mutated Atp5a $1^{\mathrm{Mom} 2 \mathrm{R}}$ allele with those carrying the wild-type Atp5a1 $1^{+}$allele. Twenty DBA.B6 Apc $\mathrm{Min} /+$ mice were randomly selected from the N7-N16 backcross generations and genotyped to determine whether they carried mutant or wild-type Atp5a1 alleles. The average polyp number $( \pm \mathrm{SD})$ for the 10 mice carrying the mutant Atp5a1 ${ }^{\text {Mom } 2 R}$ allele was $9.6 \pm 4.8$ polyps, whereas the average polyp number $( \pm \mathrm{SD})$ for the 10 mice carrying the wild-type Atp5a1+ allele was
$78.3 \pm 32.9$ polyps. Additional offspring have shown an identical relationship (data not shown). Thus, there is a 100\% concordance between the presence of the mutant Atp5a1 allele and resistance to $A p c^{M i n}$-induced intestinal polyposis.

\section{Mechanism of protection from polyp development by the Mom2 locus}

The finding of a mutation in the Atp5a1 gene suggested a potential mechanism, whereby the formation of polyps is inhibited in the presence of the mutation. Since the Atp5a1 gene is essential for aerobic respiration (Comelli et al. 1998, 2003; Schnaufer et al. 2005), its absence would result in cell death. This action would be cell autonomous. B6 Apc $\mathrm{Min} / \mathrm{+}^{\mathrm{m}}$ mice develop polyps along the intestinal tract; nearly $100 \%$ of polyps that develop in the small intestine occur by somatic recombination, which results in loss of heterozygosity (LOH) for the $A p c^{M i n}$ mutation (Shoemaker et al. 1998; Haigis et al. 2002, 2004; Haigis and Dove 2003). Therefore, if the $M o m 2^{R}$ mutation acted in a dominant fashion, its action would be independent of whether it was located on the same chromosome as the $A p c^{\mathrm{Min}}$ allele. However, if the mechanism of action were by $\mathrm{LOH}$, then the mutant Atp5a1 allele would only prevent polyps when it was on the same chromosome as the $A p c^{\mathrm{Min}}$ mutation (in cis); elimination of both the wild-type Apc and Atp5a1 genes on the wild-type homolog would lead to cell death, since there would no longer be a functional Atp5a1 gene.

One method to test this hypothesis is to determine polyp number in mice where the $M o m 2^{R}$ mutation resides on the same chromosome as the $A p c^{M i n}$ mutation (in cis) as opposed to the $M o m 2^{R}$ mutation and the $A p c^{M i n}$ mutation residing on different chromosome 18 homologs (in trans). Crosses were performed to generate offspring with the $M o m 2^{R}$ mutation in both the cis and trans configurations with respect to the $A p c^{M i n}$ mutation (Fig. 3). Quantitation of the number of polyps was performed on progeny aged for $150 \mathrm{~d}$. Control mice that carried only the $A p c^{M i n}$ mutation developed an average of 88 polyps in the small intestine, whereas those mice that carried $A p c^{M i n}$ and $M o m 2^{R}$ on the same chromosome (in cis) developed a significantly lower average of only six polyps (Student's $t$-test, $P<0.0001$ ); these data are consistent with our previous findings for the Mom $2^{R}$ phenotype (Silverman et al. 2002, 2003). However, mice that carried the $A p c^{\mathrm{Min}}$ and $M o m 2^{R}$ mutations on different homologs (in trans) developed an average of 99 polyps, which is not significantly different from the $A p c^{\mathrm{Min}}$-only control group (Student's $t$-test, $P>0.5$ ). The results shown in Figure 3 clearly demonstrate that on a DBA background, $M o m 2^{R}$ functions as a potent suppressor of polyp formation only when in cis with respect to the $A p c^{M i n}$ mutation.

Previous studies have shown that on a B6 background, polyps that develop have not only lost their $\mathrm{Apc}^{+}$allele, but have lost the entire chromosome 18 (Shoemaker et al. 1998; Haigis and Dove 2003; Haigis et al. 2004). We determined whether LOH for $\mathrm{Apc}^{+}$is occurring in adenomas from $\mathrm{Apc}^{\mathrm{Min} /+}$ mice compared with adenomas from $A p c^{M i n /+} \mathrm{Mom}^{R /+}$ mice (Fig. 4). The data clearly show that the majority of adenomas (12/16) from $A p c^{\mathrm{Min} /+}$ mice have lost their $A p c^{+}$allele, whereas only one adenoma $(1 / 21)$ from $A p c^{\mathrm{Min} /+} \mathrm{Mom}^{R /+}$ mice has lost its $\mathrm{Apc}^{+}$allele $\left(P<10^{-7}\right)$. Histopathological analysis of the adenomas used in the $\mathrm{LOH}$ analysis revealed that three of 21 tumors in $\mathrm{Apc}^{\mathrm{Min} /+} \mathrm{Mom}^{\mathrm{R/+}}$ mice progressed to carcinomas, whereas none of the adenomas in $\mathrm{Apc}^{\mathrm{Min} / \mathrm{+}}$ mice progressed (Figs. 4, 5). 
A

8030462N17Rik

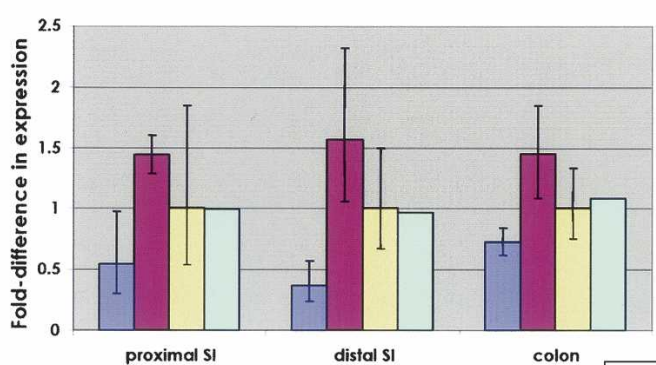

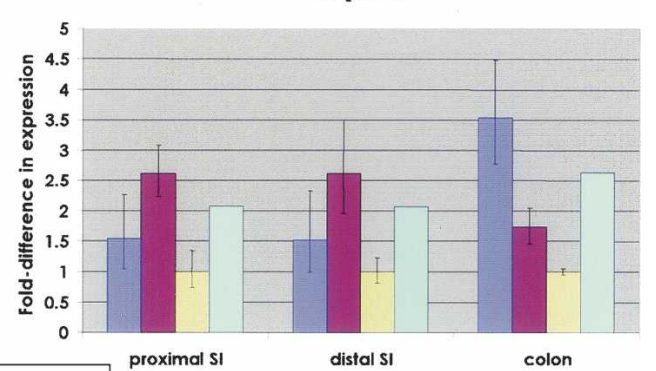

colon

\section{D2}

D2. B6 Mom2 $2^{\mathrm{R} /+}$

$\square$ predicted Wt Het

B

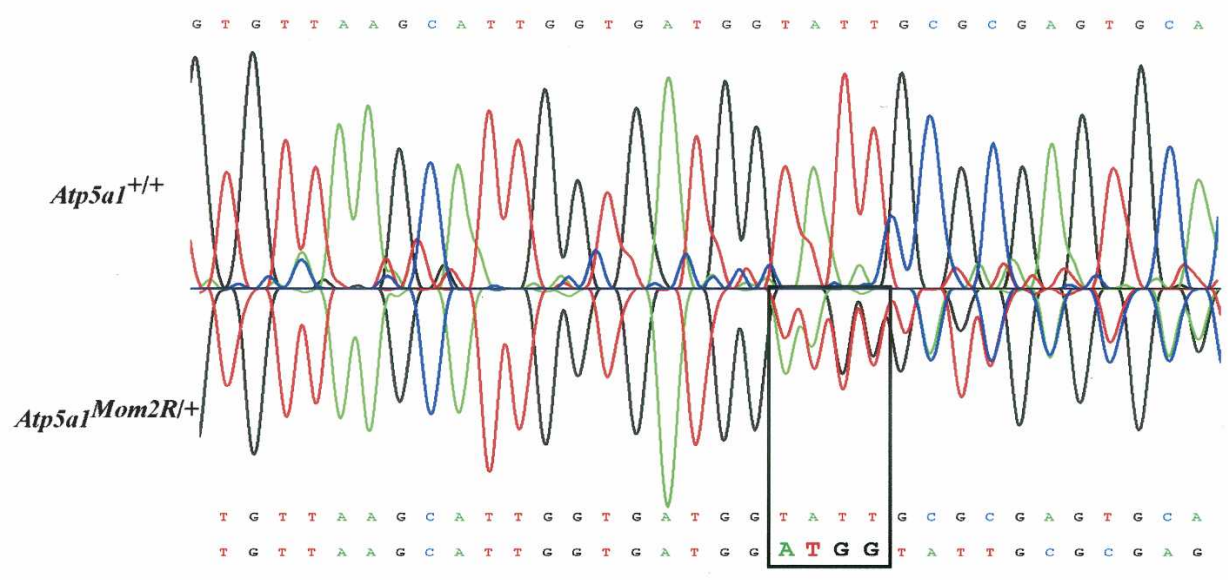

C

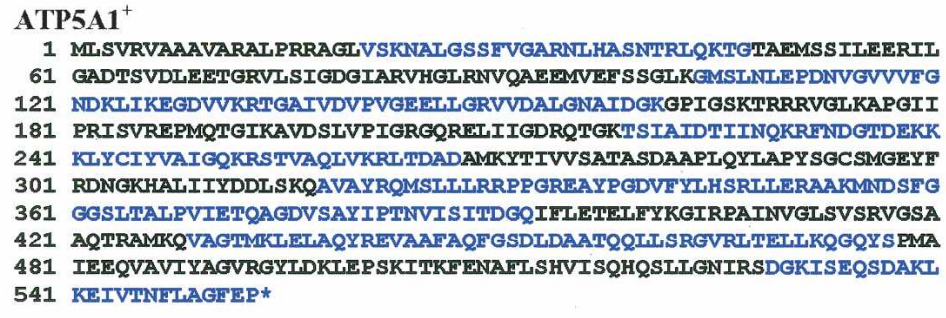

ATP5A1 ${ }^{\text {Mom2R }}$

1 MUSVRVAAAVARAI RRRAGLVSKNAI GS S FVARMLHASNTRIQKTGTAEMSSIIEERTI

61 GADTSVDLEETGRVLSIGDGWYCASARAEECS SRGDGGILFRLKGYVPELGIROCWSCRV 121 WE *

Figure 2. The coding region of the Atp5a1 gene contains a 4-bp insertion. (A) Results of the real-time PCR analysis of intestinal expression of Atp5a1 and $8030462 N 17 R i k$ expression in B6, DBA, and DBA.Mom $2^{R /+}$ congenic mice. A graphical representation of the relative expression levels of Atp5a1 and $8030462 \mathrm{~N} 17 \mathrm{Rik}$ in the proximal small intestine, distal small intestine, and colon are shown. Experimentally determined expression levels in wild-type B6, wild-type DBA, and the Mom $2^{R /+}$ congenic are shown. The predicted WT bar indicates the expected expression level in the Mom $2^{R /+}$ congenic animal, assuming 50\% contribution from both parental alleles. Atp5a1 reproducibly demonstrated an expression of 50\% of the DBA/2 J allele, with no contribution from the B6 allele. 8030462N17Rik was representative of the other genes that mapped to the congenic interval, demonstrating an expression level equivalent to the predicted level (Supplemental Methods 1). (B) The sequence of exon 3 of the Atp5a1 gene in a Mom2 ${ }^{R /+}$ mouse reveals a divergence beginning after the $100^{\text {th }}$ nucleotide of exon 3. The mutation is a 4-bp duplication of ATGG (shown in box) within exon 3 . (C) The amino acid sequence of the wild-type Atp5a1 gene is shown in comparison to the amino acid sequence of the mutant Atp5a ${ }^{\text {Mom } 2 R}$ allele. The 4-bp insertion results in a frameshift that is predicted to generate a severely truncated protein.

\section{Discussion}

The observation that the $M o m 2^{R}$ locus carried a recessive embryonic lethal mutation initially enabled the use of an exclusion mapping technique to identify the Mom2 gene as well as to pro- vide a testable hypothesis for $M o m 2^{R}$ function. This strategy excludes any marker homozygous for the B6 allele within the Mom2 region as being a part of the Mom2 locus (Fig. 1). This exclusion mapping technique should be applicable to any mutation that results in embryonic lethality (Williams 1999). Our mapping re-

\section{Genome Research}

www.genome.org 
A

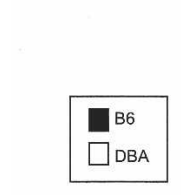

$\square$ B6
$\square$ DBA

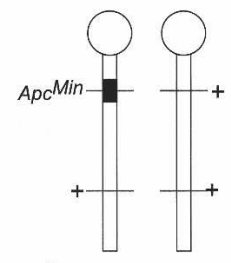

Polyp number in small intestine \pm sd

Number of progeny
$88 \pm 28$

5
B

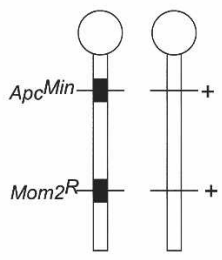

$6 \pm 2$

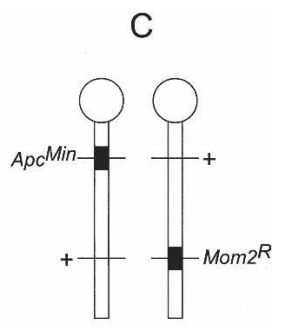

$99 \pm 27$

Figure 3. The cis-trans test reveals that the $M o m 2^{R}$ mutation functions only when in cis with the $A p C^{M i n}$ mutation. Two crosses were established to test whether Mom $2^{R}$ could function in trans as well as in cis. Three mating cages of DBA.B6 Mom2 $2^{R /+} \times$ DBA.B6 $\mathrm{ApC}^{\mathrm{Min} /+}$ mice produced progeny that carried only the $A p C^{\mathrm{Min}}$ mutation on chromosome $18(A)$ or progeny that carried the $A p c^{\mathrm{Min}}$ mutation on one chromosome 18 homolog and the $M o m 2^{R}$ mutation on the other chromosome 18 homolog ( $C$, in trans). Three mating cages of DBA/2J $\times$ DBA.B6 $\mathrm{Apc}^{\mathrm{Min} /+}, \mathrm{Mom}^{R /+}$ mice produced progeny that carried both the $A p c^{\mathrm{Min}}$ and $M o m 2^{R}$ mutations on the same chromosome 18 homolog (B, in cis). All parents of these progeny were at the N9-N12 backcross generations. The chromosomes show the positions of the Apc and Mom2 alleles on chromosome 18 homologs. Below the chromosomes is shown the average number of polyps \pm standard deviation. Statistical analyses showed that there is no significant difference in polyp numbers between the control group carrying only the Apc ${ }^{\mathrm{Min}}$ allele and the group that has $A p C^{\text {Min }}$ and Mom $2^{R}$ in trans. ( $A$ vs. $C, P>0.5$ ). In contrast, the only progeny that show highly significant differences with decreased polyp numbers is the $A p C^{\text {Min }}$ group that has Mom $2^{R}$ in cis ( $B$ vs. $A, P<0.0001 ; B$ vs. $C, P<0.0001)$.

sults from the intersubspecific intercross, which utilized the phenotype of lethality, are consistent with the mapping results from the $\mathrm{B} 6$ and DBA backcrosses, which utilized the phenotype of polyp multiplicity (Silverman et al. 2003). While more than one gene in the region could be affected, the simplest hypothesis is that a spontaneous mutation in the Atp5a1 gene has a dominant phenotype of polyp suppression and a recessive phenotype of embryonic lethality. Understanding the biological function of the Atp5a1 gene will provide important insights concerning its potential role as a modifier of human cancer.

\section{Embryonic lethality of the $M o m 2^{R}$ mutation}

The Mom $2^{R}$ allele is an early embryonic recessive lethal mutation. In timed pregnancies, we were unable to recover homozygous $M o m 2^{R}$ embryos by $12.5 \mathrm{~d}$ of gestation. Since we propose that $M o m 2^{R}$ is a null allele for the Atp5a1 gene, leading to a nonfunctional ATP synthase $\alpha$ subunit, it is not surprising that it is a recessive lethal mutation. Silencing of the Atp5a1 gene in Trypanosoma brucei and Trypanosoma evansi results in lethality (Schnaufer et al. 2005). Mitochondrial synthesis dramatically increases during early to late blastocyst stage, comprising up to 7\% of total protein synthesis in the embryo (Taylor and Piko 1995). The energy need of developing embryos dramatically increases during the formation of the blastocoel. Anoxic respiration is the primary form of ATP production until implantation and the formation of the placenta (Houghton et al. 1996). Aerobic respiration increases during late blastocyst stage (Ginsberg and Hillman 1975). With the increasing demands for aerobic respiration and energy needs during blastocoel formation and implantation, it is likely that the homozygous $M o m 2^{R}$ embryos die around this stage of development due to their inability to produce sufficient energy for their needs.

\section{The Atp5al gene and aerobic respiration}

The Atp5a1 gene encodes the $\alpha$ subunit of the ATP synthase complex, which is composed of 16 protein subunits (Boyer 1997).

retinitis pigmentosa) and a form of Leigh syndrome (Nijtmans et al. 2001). A hypomorphic mutation in a nuclear-encoded ATP synthase chaperone, ATPAF2 (formerly known as ATP12), has been identified (De Meirleir et al. 2004). We report here the first mutation identified in the Atp5a1 gene of mice or humans.

\section{The ATP5Al gene and cancer}

The ATP5A1 gene may provide a novel target to aid in diagnostics, prevention, and/or treatment of cancer. Several studies have identified an important link between the respiratory state of cancer cells and the tendency of those cells to be malignant. The Warburg hypothesis originally proposed that cancer cells have impaired mitochondrial function leading to an elevated rate of glycolysis in tumor cells (Warburg 1956). While the identification of the genetic basis of cancer has "ruled out" the causal relationship between elevated levels of glycolysis and transformation, the basic tenet of the Warburg hypothesis has been demonstrated in many tumor types (Cuezva et al. 2002, 2004). Studies have demonstrated a significant decrease in oxidative phosphorylation with an increase in glycolysis in cancer tissues. In lung, liver, kidney, and colon carcinomas, a decrease in the expression of $A T P 5 B$ has been observed (Cuezva et al. 2002, 2004). This decrease in ATP synthase production is also associated with resistance to chemo- and radiotherapies in several cancers. Decreased expression of ATP5A1 has been detected in colon cancer cells that exhibit resistance to 5-fluorouracil in culture; however, the decrease in ATP5A1 levels may precede and contribute to the ability of these colon cancer cells to attain resistance to 5-fluorouracil (Shin et al. 2005).

In several studies, it has been demonstrated that resveratrol inhibits adenoma development in $A p c^{\mathrm{Min} /+}$ mice (Schneider et al. 2001; Ziegler et al. 2004; Sale et al. 2005). Resveratrol is a phytoalexin found in grape skins that has diverse effects on cell cycle control and is a cancer chemopreventative agent (Ulrich et al. 2005). One of its many biological effects is the binding and inhibition of the $\mathrm{F}_{1}$ subunit of ATP synthase, resulting in the inhibition of ATP production (Zheng and Ramirez 2000). Alteration 


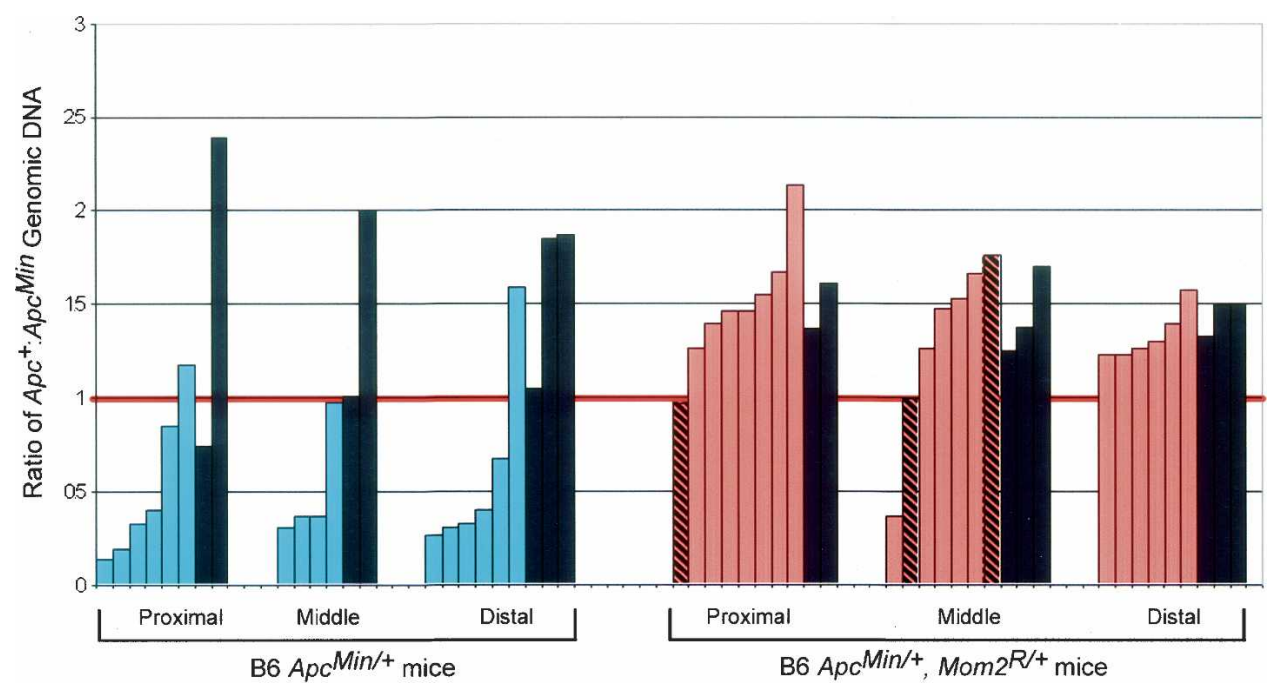

Figure 4. Quantitation of the $A p c^{+}: A p c^{M i n}$ ratio in normal and adenoma tissues in Mom $2^{R /+}$ mice. Paraffin-embedded polyp and normal tissues were microdissected from slides. DNA was isolated using Qiagen DNeasy Tissue Kit. Genomic DNA was genotyped for the Apc ${ }^{\text {in }}$ mutation, PCR products run on a $4 \%$ agarose gel, and scanned using an EtBr filter on a Typhoon scanner. Ratios were quantified using ImageQuant 5.2. Values reflect the average of duplicate trials. Black bars represent normal tissue; turquoise bars represent polyps from B6 Apc $\mathrm{Min} /+$, Mom2 $2^{+/+}$mice (aged $\sim 4-5$ mo); salmon bars represent polyps from B6 Apc Min/+ , Mom2 $2^{R /+}$ mice (aged 15-17 mo). Hatched bars represent tumors that progressed to carcinomas. A ratio of 1.0 (red line) represents the ideal Mendelian 1:1 ratio of $A p c^{+}: A p c^{\mathrm{Min}}$ alleles expected in genomic DNA from a normal heterozygote. Ratios below 0.5 suggest loss of the $A p c^{+}$allele, whereas ratios above 1.5 suggest loss of the $A p c^{\text {Min }}$ allele. The ratios of normal tissue from $A p c^{\mathrm{Min} /+}, \mathrm{Mom}^{+/+}$mice $(1.56 \pm 0.62)$ do not appear to vary from the ratios of normal tissue from $A p C^{M i n /+}$, Mom $2^{R /+}$ mice $(1.46 \pm 0.15)(P>0.6, t$-test). Interestingly, comparison of the ratios of tumor (1.38 \pm 0.35$)$ to normal $(1.46 \pm 0.15)$ tissues from $A p c^{\mathrm{Min} /+}, \mathrm{Mom}^{R /+}$ mice indicate that they are quite similar $(P>0.5, t$-test), suggesting that most tumors from $A p C^{M i n /+}, M_{0 m} 2^{R /+}$ mice retain both $A p c$ alleles. In contrast, comparison of the ratios of tumor $(0.54 \pm 0.41)$ to normal (1.56 \pm 0.62$)$ tissues from $A p C^{\mathrm{Min} /+}, \mathrm{Mom}^{+/+}$mice show a striking difference $\left(P<2 \times 10^{-4}, t\right.$-test $)$, suggesting that most polyps lose the $A p c^{+}$allele. Furthermore, the ratios of tumor tissue from $A p \mathrm{CMin/+}^{\mathrm{M}}, \mathrm{Mom}^{+/+}$mice $(0.54 \pm 0.41)$ differ significantly from the ratios of tumor tissue from $\mathrm{ApC}^{\mathrm{Min} /+}, \mathrm{Mom}^{R /+}$ mice $(1.38 \pm 0.35)\left(P<3 \times 10^{-7}, t\right.$-test). These data indicate that most tumors in $A p C^{M i n /+}, M o m 2^{R /+}$ mice arise by a mechanism different from that occurring in $\mathrm{ApC}^{\mathrm{Min} /+}, \mathrm{Mom}^{+/+}$mice.

of the mitochondrial membrane potential is one of the primary responses to treatment by resveratrol (Sareen et al. 2006). It is tempting to speculate that the mode of action of resveratrol is to inhibit $A p c^{M i n}$ adenoma formation through the inhibition of ATP synthase in the intestinal stem cells. Therefore, in the presence of resveratrol and after loss of the chromosome containing the $A p c^{+}$ allele (along with an Atp5a1 ${ }^{+}$allele), there is insufficient ATP synthesis, that results in a metabolic stress on the initiating tumor cell resulting in cell death.

The decrease in ATP synthase activity in later stages of cancer is at odds with the finding that a mutation in Atp5a1 results in a decrease of polyp multiplicity. However, this discrepancy most likely reflects the differing energy requirements for earlystage tumor initiation in contrast to later stages of cancer progression.

\section{Mechanism of polyp suppression by the $M o m 2^{R}$ mutation}

The mechanism of polyp formation on a B6 genetic background was originally proposed to result from loss of the entire chromosome containing the wild-type Apc allele (Levy et al. 1994; Luongo et al. 1994; Shoemaker et al. 1998; Haigis et al. 2004). However, current studies indicate that the loss of heterozygosity of the $\mathrm{Apc}^{+}$allele results primarily from somatic recombination, with a small fraction of polyps exhibiting chromosomal homozygosis (Haigis et al. 2002; Haigis and Dove 2003). These mechanisms provide a working hypothesis for the $M o m 2^{R}$ allele in polyp protection. Inhibition of ATP synthase activity using oligomycin has demonstrated that cells experiencing a 65\%-85\% decrease in ATP synthase activity undergo apoptosis in vitro (Comelli et al. 1998, 2003). Therefore, any mechanism resulting in loss of both wild-type Atp5a1 alleles should cause cell death, due to the absence of ATP synthase activity. Since the chromosome carrying the $A p c^{\mathrm{Min}}$ allele also carries the mutant Atp5a1 allele, loss of the $\mathrm{ApC}^{+} \mathrm{Mom}^{+}$chromosome 18 would result in loss of the only functional Atp5a1 allele (Fig. 6A). Furthermore, any stem cell in intestinal crypts that undergoes somatic recombination and becomes homozygous for the $A p c^{M i n}$ mutation (which would normally lead to polyposis), would undergo cell death in $M o m 2^{R /+}$ mice, due to the fact that the cell is now homozygous for the Atp5a1 mutation (Fig. 6B). Similarly, chromosomal homozygosis of the chromosome carrying both the $A p c^{\mathrm{Min}}$ and Atp5a1 mutations (cis configuration) would also result in cell death (Fig. 6C). Thus, when the Mom $2^{R}$ allele is in cis with the $A p c^{M i n}$ mutation, $\mathrm{LOH}$ of the wild-type chromosome results in a dramatic $\sim 90 \%$ reduction in polyp formation. It is interesting to note that this degree of reduction in polyp numbers is comparable and consistent with the decrease in polyp numbers seen in $A p c^{M i n}$ mice carrying the Robertsonian translocation $\mathrm{Rb}(7.18) 9 \mathrm{Lub}$, which has been shown to suppress somatic recombination in $A p c^{M i n}$ mice (Haigis and Dove 2003).

\section{How do the few polyps arise in $\mathrm{Apc}^{\mathrm{Min} /+}, \mathrm{Mom} 2^{R /+}$ mice?}

The finding of a few polyps in some mice that carry $A p c^{M i n}$ and $M o m 2^{R}$ in cis suggested several mechanisms by which intestinal cells can escape polyp suppression (Fig. 6). The data indicate that the few polyps that form in $M o m 2^{R /+}$ animals maintain heterozygosity for both Apc alleles (Fig. 4). Therefore, since the wildtype chromosome 18 is retained, the $\mathrm{Apc}^{+}$allele must be inactivated. This event could occur by either epigenetic silencing (Esteller et al. 2000; Chen et al. 2005) or somatic mutation (Miyaki 


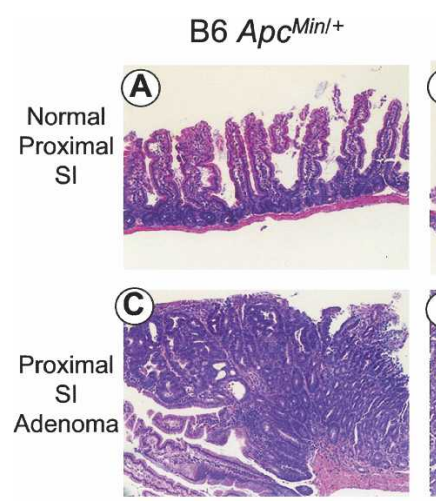

B6 Apc $c^{\mathrm{Min} /+}, \mathrm{Mom}^{\mathrm{R} /+}$
(B)

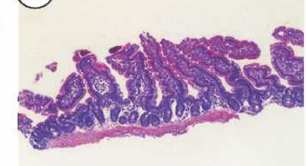

Normal

Middle SI

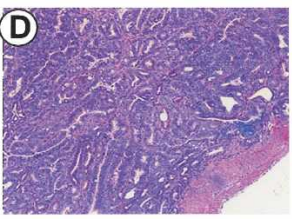

Proximal SI

Adenoma
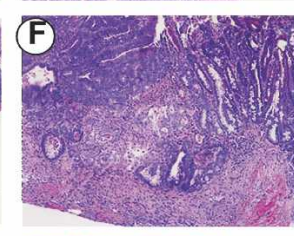

Proximal

$\mathrm{SI}$

Carcinoma
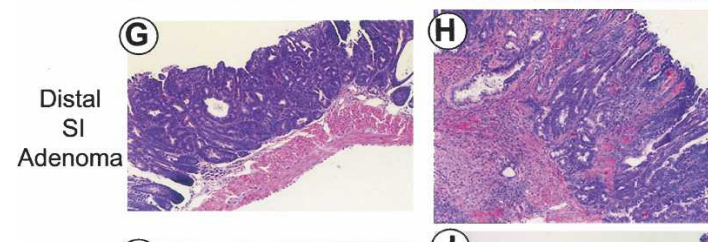

Middle

SI

Carcinoma
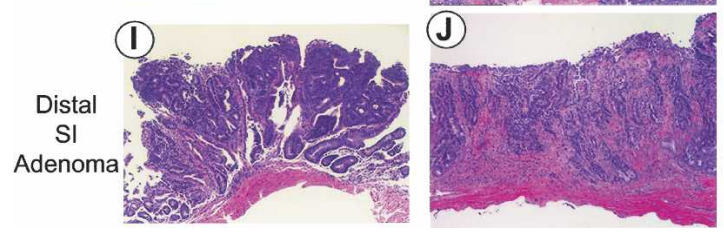

Middle

Carcinoma
Figure 5. Polyps from $\mathrm{B} 6 \mathrm{ApC}^{\mathrm{Min} /+}, \mathrm{Mom} 2^{R /+}$ mice tend to be more advanced than polyps from B6 $\mathrm{ApC}^{\mathrm{Min} /+}$ mice. Microdissected polyps were stained with hematoxylin and eosin and photographed on a Nikon Eclipse E600 microscope at $100 \times$ magnification. $(A, C, E, G, I)$ Isolated from $\mathrm{B} 6 \mathrm{ApC}^{\mathrm{Min} /+} \mathrm{Mom}^{+/+}$mice as indicated. $(B, D, F, H, D)$ Isolated from B6 Apc $\mathrm{Min} /+^{\mathrm{Mom} 2^{R /+}}$ mice as indicated. Size measurements revealed that adenomas in $\mathrm{ApC}^{\mathrm{Min} /+} \mathrm{Mom}^{\mathrm{R/+}}$ mice were threefold larger than the adenomas in $A p C^{\mathrm{Min} /+} \mathrm{Mom}^{+/+}$mice $(P=0.03)$ (data not shown).

et al. 1995; Crabtree et al. 2003) of the $A p c^{+}$allele. Alternatively, somatic recombination could occur between the $A p c^{M i n}$ and $M o m 2^{R}$ mutations, resulting in a chromosome that has only the $A p c^{M i n}$ mutation and a wild-type Atp5a1 allele. Chromosomal homozygosis (Haigis et al. 2002, 2004) and/or loss of the reciprocal recombinant would result in a cell that carries only the $A p c^{M i n}$ mutation and the $A t p 5 a 1^{+}$gene, thus resulting in a polyp (Fig. 6D-F).

Several features of the adenomas that develop in $A p c^{\mathrm{Min} /+}$ $M o m 2^{R /+}$ mice are reminiscent of human tumorigenesis. The most common mechanisms of LOH for the APC gene involve: (1) epigenetic silencing, (2) base substitutions within the coding region, or (3) small intragenic deletions (Fearnhead et al. 2001). However, human colon tumors have not been shown to lose the entire chromosome carrying the $A P C$ gene, as has been demonstrated for chromosome 18 in $\mathrm{B} 6 \mathrm{ApC}^{\mathrm{Min} /+}$ mice (Levy et al. 1994; Luongo et al. 1994). Therefore, retention of the $A p c^{+}$allele in polyps from $A p c^{M i n /+} \mathrm{Mom}^{R /+}$ mice is one feature that accurately recapitulates human tumorigenesis. In addition, the heavy polyp load in $\mathrm{B} 6 \mathrm{ApC}^{\mathrm{Min} /+}$ mice usually leads to death by 5-6 mo of age, and adenomas in these mice rarely progress to carcinomas (Halberg et al. 2000; Cooper et al. 2005). In contrast, the light polyp load in $\mathrm{Apc}^{\mathrm{Min} /+} \mathrm{Mom} 2^{R /+}$ mice allows for a significantly longer lifespan ( $>2 \mathrm{yr}$ ) and $~ 15 \%$ of adenomas progress to carcinomas by $15-17$ mo of age (Figs. 4,5 ). Whether progression is related to the longer lifespan or, alternatively, to the retention of the $A p c^{+}$chromosome, remains to be determined. Regardless of the mechanism, $A p c^{\mathrm{Min} /+} \mathrm{Mom}^{R /+}$ mice provide informative vehicles to test therapeutic agents designed to prevent tumor progression.

Generation of congenic mice and the chance for any mutation on mouse chromosome 18 to result in a similar phenotype for Min

Our identification of a recessive lethal mutation that is physically linked to the $A p c^{M i n}$ mutation suggests that a recessive cell-lethal mutation in any gene on mouse chromosome 18 would result in a reduction in the number of intestinal polyps (if it resided in cis with the $A p c^{M i n}$ mutation). This statement would be true in any mouse strains (such as B6) in which the major mechanism of $\mathrm{Apc}^{+}$inactivation involved loss of the chromosome carrying the $A p c^{+}$allele. In addition, continued selection for a specific mutation or chromosomal region (such as occurs during the derivation of congenic lines) may increase the chances of such mutations becoming fixed within a colony. The $M o m 2^{R}$ mutation may have been perpetuated within the $A p c^{\text {Min }}$ colony at The Jackson Laboratory, because the mice that carried $M o m 2^{R}$ would have appeared more fit, had higher reproductive capacity, and lived longer than their susceptible $M o m 2^{+}$littermates. Such mutations, if providing a selective advantage, could eventually become the predominant allele within a colony, thus altering the characteristics of the inbred strain over time.

Potential examples of other such mutations occurring on the $A p c^{M i n}$ chromosome are suggested in the literature. For example, Wilson et al. (1997) reported that B6 Apc Min/+ mice developed an average of 25.4 polyps (range $20-38$ polyps) when aged for $120 \mathrm{~d}$ (Wilson et al. 1997); a later publication using the same Min colony showed an average tumor number of only 18 polyps (Wagenaar-Miller et al. 2003). Similarly, Javid et al. (2005) reported an average of $18.9 \pm 6.8(\mathrm{SD})$ polyps in C57BL/6J Apc Min mice obtained directly from The Jackson Laboratory. These numbers are substantially smaller and have a much lower variance than the number of polyps commonly reported for B6 $\mathrm{Apc} \mathrm{Min/+}$ mice (Siracusa et al. 2004). These almost uniform types of polyp distributions suggest that other loci tightly linked to the $A p c^{\text {Min }}$ mutation are responsible for resistance to polyp formation. In contrast, a recent report has identified a novel modifier closely linked to $A p c^{M i n}$ that results in a dramatic increase in polyp multiplicity that arose during selective inbreeding of a hybrid strain (Haines et al. 2005).

Several publications that describe polyp multiplicity in $A p c^{\mathrm{Min}}$ mice on a $\mathrm{C} 57 \mathrm{BL} / 6 \mathrm{~J}$ (or congenic) background demonstrate that there exists much variation in polyp multiplicity (Song et al. 2000; Tucker et al. 2002; Mai et al. 2003; Haines et al. 2005; Moran et al. 2005). While some of this variation might be explained by environmental differences, it is clear from our studies that heterogeneity exists within inbred strains of mice, and could be due to the presence of spontaneous mutations that alter the genetic "homogeneity" of a model system. 

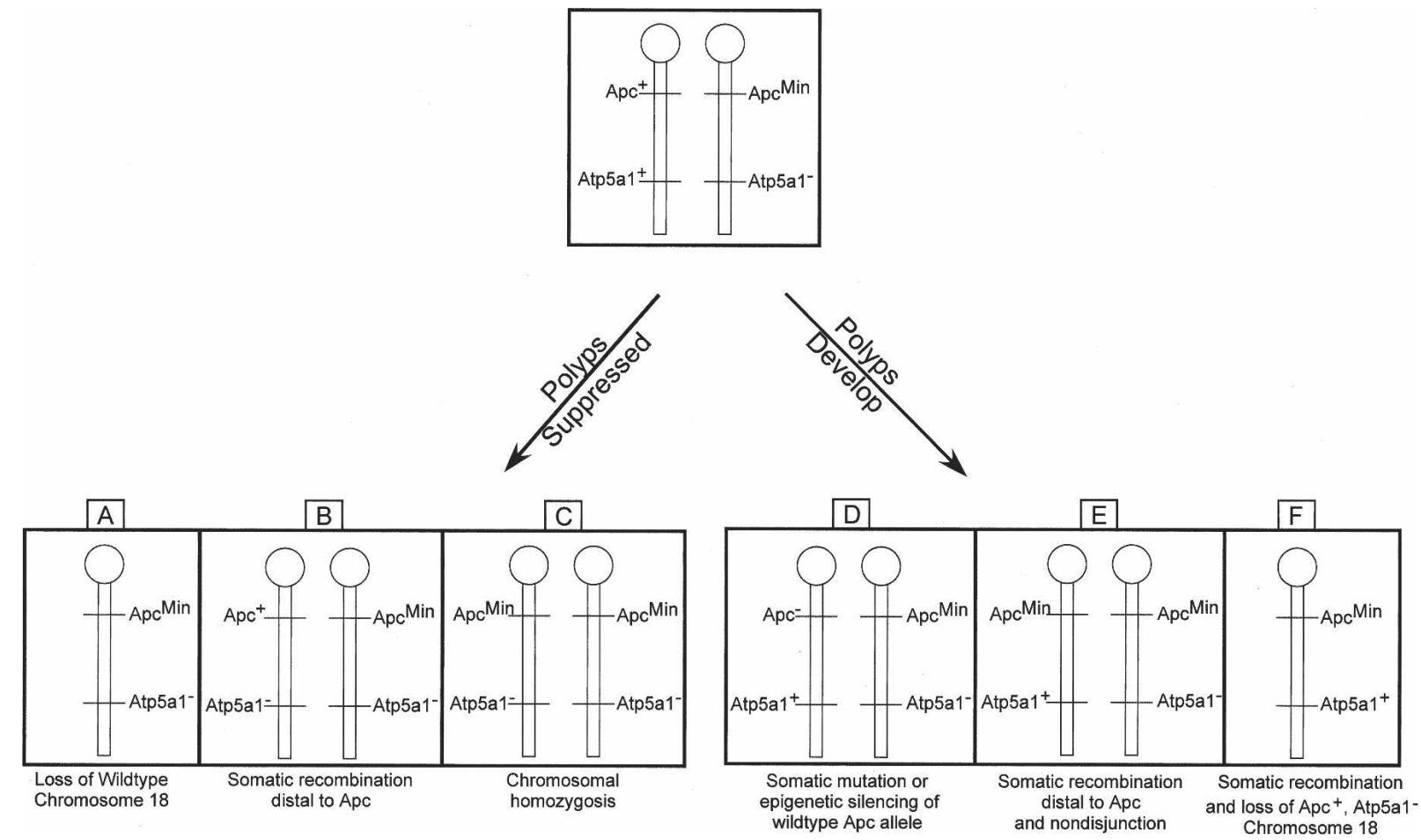

Figure 6. Mechanism of $\mathrm{Mom}^{R}$ suppression of $A p c^{\mathrm{Min}}$-induced polyposis. The chromosome 18 homologs present in an $\mathrm{ApC}^{\mathrm{Min} /+} \mathrm{Atp}^{\mathrm{Aa}} \mathrm{1}^{+/-}$mouse are shown. Previous work has shown that in the B6 mouse, the major mechanism of polyp formation involves loss of the entire wild-type chromosome 18 $(A)$. If this occurs, a cell would lose its wild-type $A t p 5 a 1^{+}$allele and die. Similarly, if somatic recombination distal to Apc (B) or chromosomal homozygosis

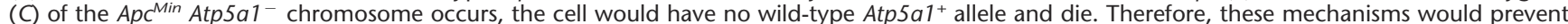
stem cells from developing into polyps. However, if both chromosome 18 homologs remain $(D)$, polyps could develop in cells that have their wild-type $A p c$ allele silenced or inactivated. In this case, a cell would retain its wild-type Atp5a $1^{+}$allele. Similarly, recombination between the Apc and Atp5a1 loci could occur, followed by loss of the chromosome containing the $A p c^{+}$and $A t p 5 a 1^{-}$alleles $(F)$ or nondisjunction $(E)$. In these cases, cells retaining the mutant $A p C^{M i n}$ allele and the wild-type Atp5a1+ allele could form polyps.

\section{Methods}

\section{Mice}

Mice were bred at the AAALAC-accredited TJU Animal Facility, except for the original C57BL/6J (B6) $A p c^{\mathrm{Min} /+}$ males, DBA/2J (DBA) mice, and CAST/Ei (CAST) mice, which were purchased from The Jackson Laboratory. Animals were fed laboratory autoclavable rodent diet 5010 (PMI Nutrition International, Inc.). Special husbandry protocols were followed to ensure both reproductive fecundity and viability of CAST mice; these mice were housed in a designated "quiet room" in large microisolator cages with specially designed lids to prevent escape. Cages were prepared with autoclaved aspen shavings, 2-3 nestlets, food, and water bottles.

\section{Genomic DNA isolation and sequencing}

Genomic DNA was isolated from tail biopsies as described (Silverman et al. 2002). Genomic DNA from organs was isolated using a standard phenol-chloroform method and resuspended in water (Sambrook and Russell 2001). Genomic DNA was subjected to PCR using primer pairs derived from intronic sequences designed to amplify exons of Atp5a1, Ccdc5, and Pstpip2 (Supplemental Tables 2, 3,4). Resulting fragments were purified and sequenced with a 377-DNA Sequencer from ABI Prism by the KCC Nucleic Acids Facility. Sequencing was performed using both forward and reverse primers and the resulting sequences were aligned using BLAST (http://www.ncbi.nlm.nih.gov/BLAST/).

\section{DBA.B6 Mom2 $2^{R /+}$ intercross}

Congenic mice were generated through selection and backcrossing of DBA.B6 $A p c^{M i n /+}, M o m 2^{R /+}$ N\# mice with DBA animals; offspring were genotyped by PCR for the $A p c^{M i n}$ mutation as well as for the Mom2 locus using the flanking markers D18Mit186 and D18Mit213 (Silverman et al. 2003). Progeny were selected that carried the Mom2-resistant region $\left(\mathrm{Mom}^{R /+}\right)$, but did not carry the $A p c^{M i n}$ mutation. DBA.B6 Mom2 $2^{R /+}$ animals from the N4-N5 backcross generations were intercrossed to generate $M o m 2^{R / R}$ homozygotes. Each $\mathrm{F}_{2}$ offspring was genotyped for the Mom2 region by PCR with D18Mit80 and D18Mit213 as described (Silverman et al. 2003), and to determine whether they were $M o m 2^{R / R}$, $M o m 2^{R /+}$, or $\mathrm{Mom}^{+/+}$. Four offspring that showed recombination within the Mom2 region were not informative and were therefore excluded from the analyses (data not shown).

\section{Genotyping for molecular markers}

The $A p c^{\text {Min }}$ mutation was genotyped by modification of a previously published protocol (Luongo et al. 1994) as described (Silverman et al. 2003). SSLP markers were selected based on polymorphisms that were identified between the B6 and CAST strains. Primer pairs were purchased from Invitrogen. A total of 50-100 ng of genomic tail DNA was amplified along with $50 \mathrm{ng}$ each of the oligomers, $0.5 \mathrm{mM}$ of each nucleotide (dCTP, dGTP, dTTP, and dATP), in a buffer (final concentration $50 \mathrm{mM} \mathrm{KCl}, 10$ $\mathrm{mM}$ Tris- $\mathrm{HCl}$ at $\mathrm{pH} 8.0,1.5 \mathrm{mM} \mathrm{MgCl}_{2}$, and $0.1 \mathrm{mg} / \mathrm{mL}$ gelatin), along with $5 \mathrm{U} / \mu \mathrm{L}$ of Taq DNA polymerase (Roche Molecular

\section{Genome Research}

www.genome.org 
Biochemicals). Samples were amplified under the following conditions: one cycle at $94^{\circ} \mathrm{C}$ for $4 \mathrm{~min}$, followed by 35 cycles at $94^{\circ} \mathrm{C}$ for $30 \mathrm{sec}, 58^{\circ} \mathrm{C}$ or $60^{\circ} \mathrm{C}$ for $45 \mathrm{sec}, 72^{\circ} \mathrm{C}$ for $30 \mathrm{sec}$, and ending with one cycle at $72^{\circ} \mathrm{C}$ for $7 \mathrm{~min}$. Polymorphisms of $10 \mathrm{bp}$ or higher were detected on 3\% TBE agarose gels and visualized by staining with EtBr (Sambrook and Russell 2001). If the polymorphism was $<10 \mathrm{bp}$, the forward primer was end-labeled with $\left[\gamma^{32} \mathrm{P}\right] \mathrm{dATP}$ using polynucleotide kinase prior to PCR (Sambrook and Russell 2001); 6\% denaturing polyacrylamide urea gels were used for resolution of the radiolabeled products, followed by autoradiography (Sambrook and Russell 2001).

\section{Identification of new SSLP markers}

Candidate SSR marker primer pairs were generated using the Mouse Genome SSR search website, Massachusetts General Hospital (Charlestown, MA; http://danio.mgh.harvard.edu/ mouseMarkers/musssr.html). Several primer pairs (D18Kcc\# loci) in the Mom2 region detected polymorphisms between B6, DBA, and CAST mice (Supplemental Table 1).

\section{Genotyping for the mutation in the Atp5al gene}

The mutation in the Atp5a1 gene was detected by designing primers that incorporated the 4-bp insertion into the sequence. The forward primer (5'-GTTAAGCATTGGTGATGGATGG-3') lies at the site of the insertion (middle of exon 3 ) and will only bind the mutant Atp5a1 allele. The reverse primer (5'-TGAGA GAGCAAAGCTACAGATCC-3') lies within intron 3. PCR reactions contained $100 \mathrm{ng}$ of genomic DNA, $50 \mathrm{ng}$ each of the forward and reverse oligomers, $0.5 \mathrm{mM}$ of each nucleotide (dCTP, dGTP, dTTP, and dATP), in a buffer (final concentration $50 \mathrm{mM}$ $\mathrm{KCl}, 10 \mathrm{mM}$ Tris- $\mathrm{HCl}$ at $\mathrm{pH} 8.0,1.5 \mathrm{mM} \mathrm{MgCl}_{2}$, and $0.1 \mathrm{mg} / \mathrm{mL}$ gelatin), along with $5 \mathrm{U} / \mu \mathrm{L}$ of Taq DNA polymerase (Roche Molecular Biochemicals). Samples were amplified under the following conditions: one cycle at $94^{\circ} \mathrm{C}$ for $4 \mathrm{~min}$, followed by 35 cycles at $94^{\circ} \mathrm{C}$ for $45 \mathrm{sec}, 60^{\circ} \mathrm{C}$ for $45 \mathrm{sec}, 72^{\circ} \mathrm{C}$ for $45 \mathrm{sec}$, ending with one cycle at $72^{\circ} \mathrm{C}$ for $7 \mathrm{~min}$. A 147-bp fragment was detected when the mutant Atp5a1 allele was present, whereas no fragment was detected in mice homozygous for the wild-type Atp5a1 gene.

\section{Assessment of intestinal polyp number in $A p c^{\mathrm{Min}}$ mice}

$A p c^{\mathrm{Min} /+}$ mice generated from crosses of DBA $\times$ DBA.B6 $\mathrm{Apc}^{\mathrm{Min} /+}$ mice were aged and then euthanized by $\mathrm{CO}_{2}$ asphyxiation. The small intestine and colon were dissected and cleared of residual debris as described (Koratkar et al. 2002, 2004). Polyps were counted using a Nikon SMZ-U dissection scope at $15 \times$ magnification.

\section{Acknowledgments}

We thank Sarah Grant, Michael Matrone, Michael Powell, Meagan Orth, Richard Crist, and Paul Rowlands for excellent technical assistance. We thank Ed Pequinot for assistance with statistical analyses. A.A.B., K.A.S., and R.K. were supported in part by N.I.H. Training Grant T32-CA09678, and by a CGS Alumni Fellowship from TJU. Research was supported by grants from the NCI and the Pennsylvania Department of Health, which specifically disclaims responsibility for any analyses, interpretations, or conclusions.

\section{References}

Boyer, P.D. 1997. The ATP synthase-A splendid molecular machine. Annu. Rev. Biochem. 66: 717-749.

Chen, J., Rocken, C., Lofton-Day, C., Schulz, H.-U., Muller, O., Kutzner, N., Malfertheiner, P., and Ebert, M.P.A. 2005. Molecular analysis of
APC promoter methylation and protein expression in colorectal cancer metastasis. Carcinogenesis 26: $37-43$.

Comelli, M., Londero, D., and Mavelli, I. 1998. Severe energy impairment consequent to inactivation of mitochondrial ATP synthase as an early event in cell death: A mechanism for the selective sensitivity to $\mathrm{H}_{2} \mathrm{O}_{2}$ of differentiating erythroleukemia cells. Free Radic. Biol. Med. 24: 924-932.

Comelli, M., Di Pancrazio, F., and Mavelli, I. 2003. Apoptosis is induced by decline of mitochondrial ATP synthesis in erythroleukemia cells. Free Radic. Biol. Med. 34: 1190-1199.

Cooper, H.L., Chang, W.C., Coudry, R., Gary, M.A., Everly, L., Spittle, C.S., Wang, H., Litwin, S., and Clapper, M.L. 2005. Generation of a unique strain of multiple intestinal neoplasia $\left(A p c^{+/ M i n-F C C C}\right)$ mice with significantly increased numbers of colorectal adenomas. Mol. Carcinog. 44: 31-41.

Cormier, R.T., Hong, K.H., Halberg, R.B., Hawkins, T.L., Richardson, P., Mulherkar, R., Dove, W.F., and Lander, E.S. 1997. Secretory phospholipase Pla2g2a confers resistance to intestinal tumorigenesis. Nat. Genet. 17: 88-91.

Cormier, R.T., Bilger, A., Lillich, A.J., Halberg, R.B., Hong, K.H., Gould, K.A., Borenstein, N., Lander, E.S., and Dove, W.F. 2000. The $M o m 1^{A K R}$ intestinal tumor resistance region consists of Pla2g2a and a locus distal to D4Mit64. Oncogene 19: 3182-3192.

Crabtree, M., Sieber, O.M., Lipton, L., Hodgson, S.V., Lamlum, H., Thomas, H.J., Neale, K., Phillips, R.K., Heinimann, K., and Tomlinson, I.P. 2003. Refining the relation between 'first hits' and 'second hits' at the APC locus: The 'loose fit' model and evidence for differences in somatic mutation spectra among patients. Oncogene 22: $4257-4265$

Cuezva, J.M., Krajewska, M., de Heredia, M.L., Krajewski, S., Santamaria, G., Kim, H., Zapata, J.M., Marusawa, H., Chamorro, M., and Reed, J.C. 2002. The bioenergetic signature of cancer: A marker of tumor progression. Cancer Res. 62: 6674-6681.

Cuezva, J.M., Chen, G., Alonso, A.M., Isidoro, A., Misek, D.E., Hanash, S.M., and Beer, D.G. 2004. The bioenergetic signature of lung adenocarcinomas is a molecular marker of cancer diagnosis and prognosis. Carcinogenesis 25: 1157-1163.

De Meirleir, L., Seneca, S., Lissens, W., De Clercq, I., Eyskens, F., Gerlo, E., Smet, J., and Van Coster, R. 2004. Respiratory chain complex V deficiency due to a mutation in the assembly gene ATP12. J. Med. Genet. 41: 120-124.

Demant, P. 2003. Cancer susceptibility in the mouse: Genetics, biology and implications for human cancer. Nat. Rev. Genet. 4: 721-734.

Dietrich, W.F., Lander, E.S., Smith, J.S., Moser, A.R., Gould, K.A., Luongo, C., Borenstein, N., and Dove, W. 1993. Genetic identification of Mom-1, a major modifier locus affecting Min-induced intestinal neoplasia in the mouse. Cell 75: 631-639.

Dragani, T.A. 2003. 10 years of mouse cancer modifier loci: Human relevance. Cancer Res. 63: 3011-3018.

Esteller, M., Sparks, A., Toyota, M., Sanchez-Cespedes, M., Capella, G. Peinado, M.A., Gonzalez, S., Tarafa, G., Sidransky, D., Meltzer, S.J., et al. 2000. Analysis of adenomatous polyposis coli promoter hypermethylation in human cancer. Cancer Res. 60: 4366-4371.

Fearnhead, N.S., Britton, M.P., and Bodmer, W.F. 2001. The ABC of APC. Hum. Mol. Genet. 10: 721-733.

Ginsberg, L. and Hillman, N. 1975. Shifts in ATP synthesis during preimplantation stages of mouse embryos. J. Reprod. Fertil. 43: 83-90.

Godbout, R., Pandita, A., Beatty, B., Bie, W., and Squire, J.A. 1997. Comparative genomic hybridization analysis of Y79 and FISH mapping indicate the amplified human mitochondrial ATP synthase $\alpha$-subunit gene (ATP5A) maps to chromosome $18 \mathrm{q} 12 \rightarrow \mathrm{q} 21$. Cytogenet. Cell Genet. 77: 253-256.

Gregorieff, A. and Clevers, H. 2005. Wnt signaling in the intestinal epithelium: From endoderm to cancer. Genes \& Dev. 19: 877-890.

Haigis, K.M. and Dove, W.F. 2003. A Robertsonian translocation suppresses a somatic recombination pathway to loss of heterozygosity. Nat. Genet. 33: 33-39.

Haigis, K.M., Caya, J.G., Reichelderfer, M., and Dove, W.F. 2002. Intestinal adenomas can develop with a stable karyotype and stable microsatellites. Proc. Natl. Acad. Sci. 99: 8927-8931.

Haigis, K.M., Hoff, P.D., White, A., Shoemaker, A.R., Halberg, R.B., and Dove, W.F. 2004. Tumor regionality in the mouse intestine reflects the mechanism of loss of Apc function. Proc. Natl. Acad. Sci. 101: 9769-9773.

Haines, J., Johnson, V., Pack, K., Suraweera, N., Slijepcevic, P., Cabuy, E., Coster, M., Ilyas, M., Wilding, J., Sieber, O., et al. 2005. Genetic basis of variation in adenoma multiplicity in ApcMin/+ Mom1S mice. Proc. Natl. Acad. Sci. 102: 2868-2873.

Halberg, R.B., Katzung, D.S., Hoff, P.D., Moser, A.R., Cole, C.E., Lubet, R.A., Donehower, L.A., Jacoby, R.F., and Dove, W.F. 2000. Tumorigenesis in the multiple intestinal neoplasia mouse: 
Redundancy of negative regulators and specificity of modifiers. Proc. Natl. Acad. Sci. 97: 3461-3466.

Houghton, F.D., Thompson, J.G., Kennedy, C.J., and Leese, H.J. 1996 Oxygen consumption and energy metabolism of the early mouse embryo. Mol. Reprod. Dev. 44: 476-485.

Ilyas, M., Straub, J., Tomlinson, I.P., and Bodmer, W.F. 1999. Genetic pathways in colorectal and other cancers. Eur. J. Cancer 35: 1986-2002.

Javid, S.H., Moran, A.E., Carothers, A.M., Redston, M., and Bertagnolli, M.M. 2005. Modulation of tumor formation and intestinal cell migration by estrogens in the $\mathrm{Apc}^{\mathrm{Min} /+}$ mouse model of colorectal cancer. Carcinogenesis 26: 587-595.

Kinzler, K.W. and Vogelstein, B. 1996. Lessons from hereditary colorectal cancer. Cell 87: 159-170.

Koratkar, R., Pequignot, E., Hauck, W.W., and Siracusa, L.D. 2002. The CAST/Ei strain confers significant protection against $A p c^{M i n}$ intestinal polyps, independent of the resistant modifier of Min 1 (Mom1) locus. Cancer Res. 62: 5413-5417.

Koratkar, R., Silverman, K.A., Pequignot, E., Hauck, W.W., Buchberg, A.M., and Siracusa, L.D. 2004. Analysis of reciprocal congenic lines reveals the $\mathrm{C} 3 \mathrm{H} / \mathrm{HeJ}$ genome to be highly resistant to $A p c^{\text {Min }}$ intestinal tumorigenesis. Genomics 84: 844-852.

Levy, D.B., Smith, K.J., Beazer-Barclay, Y., Hamilton, S.R., Vogelstein, B., and Kinzler, K.W. 1994. Inactivation of both APC alleles in human and mouse tumors. Cancer Res. 54: 5953-5958.

Luongo, C., Moser, A.R., Gledhill, S., and Dove, W.F. 1994. Loss of $\mathrm{Apc}^{+}$ in intestinal adenomas from Min mice. Cancer Res. 54: 5947-5952.

MacPhee, M., Chepenik, K.P., Liddell, R.A., Nelson, K.K., Siracusa, L.D., and Buchberg, A.M. 1995. The secretory phospholipase A2 gene is a candidate for the Mom1 locus, a major modifier of $A p c^{M i n}$-induced intestinal neoplasia. Cell 81: 957-966.

Mai, V., Colbert, L.H., Berrigan, D., Perkins, S.N., Pfeiffer, R., Lavigne, J.A., Lanza, E., Haines, D.C., Schatzkin, A., and Hursting, S.D. 2003. Calorie restriction and diet composition modulate spontaneous intestinal tumorigenesis in $A p c^{\mathrm{Min}}$ mice through different mechanisms. Cancer Res. 63: 1752-1755.

Mao, J.H. and Balmain, A. 2003. Genomic approaches to identification of tumour-susceptibility genes using mouse models. Curr. Opin. Genet. Dev. 13: 14-19.

Miyaki, M., Tanaka, K., Kikuchi-Yanoshita, R., Muraoka, M., and Konishi, M. 1995. Familial polyposis: Recent advances. Crit. Rev. Oncol. Hematol. 19: 1-31.

Moore, K.J. and Nagle, D.L. 2000. Complex trait analysis in the mouse: The strengths, the limitations and the promise yet to come. Annu. Rev. Genet. 34: 653-686.

Moran, A.E., Carothers, A.M., Weyant, M.J., Redston, M., and Bertagnolli, M.M. 2005. Carnosol inhibits $\beta$-catenin tyrosine phosphorylation and prevents adenoma formation in the C57BL/6J/Min/+ (Min/+) mouse. Cancer Res. 65: 1097-1104.

Nijtmans, L.G., Henderson, N.S., Attardi, G., and Holt, I.J. 2001. Impaired ATP synthase assembly associated with a mutation in the human ATP synthase subunit 6 gene. J. Biol. Chem. 276: 6755-6762.

Sale, S., Tunstall, R.G., Ruparelia, K.C., Potter, G.A., Steward, W.P., and Gescher, A.J. 2005. Comparison of the effects of the chemopreventive agent resveratrol and its synthetic analog trans 3,4,5,4'-tetramethoxystilbene (DMU-212) on adenoma development in the $\mathrm{ApC}^{\mathrm{Min}+}$ mouse and cyclooxygenase-2 in human-derived colon cancer cells. Int. J. Cancer 115: 194-201.

Sambrook, J. and Russell, D.W. 2001. Molecular cloning: A laboratory manual. Cold Spring Harbor Laboratory Press, Cold Spring Harbor, NY.

Sareen, D., van Ginkel, P.R., Takach, J.C., Mohiuddin, A., Darjatmoko, S.R., Albert, D.M., and Polans, A.S. 2006. Mitochondria as the primary target of resveratrol-induced apoptosis in human retinoblastoma cells. Invest. Ophthalmol. Vis. Sci. 47: 3708-3716.

Schnaufer, A., Clark-Walker, G.D., Steinberg, A.G., and Stuart, K. 2005. The $\mathrm{F}_{1}$-ATP synthase complex in bloodstream stage trypanosomes has an unusual and essential function. EMBO J. 24: 4029-4040.

Schneider, Y., Duranton, B., Gosse, F., Schleiffer, R., Seiler, N., and Raul, F. 2001. Resveratrol inhibits intestinal tumorigenesis and modulates host-defense-related gene expression in an animal model of human familial adenomatous polyposis. Nutr. Cancer 39: 102-107.

Shin, Y.-K., Yoo, B.C., Chang, H.J., Jeon, E., Hong, S.-H., Jung, M.-S., Lim, S.-J., and Park, J.-G. 2005. Down-regulation of mitochondrial $\mathrm{F}_{1} \mathrm{~F}_{0}$-ATP synthase in human colon cancer cells with induced 5-fluorouracil resistance. Cancer Res. 65: 3162-3170.

Shoemaker, A.R., Moser, A.R., Midgley, C.A., Clipson, L., Newton, M.A., and Dove, W.F. 1998. A resistant genetic background leading to incomplete penetrance of intestinal neoplasia and reduced loss of heterozygosity in Apc Min $/+$ mice. Proc. Natl. Acad. Sci. 95: $10826-10831$.

Silver, L.M. 1995. Mouse genetics, concepts and applications. Oxford University Press, New York.

Silverman, K.A., Koratkar, R., Siracusa, L.D., and Buchberg, A.M. 2002. Identification of the modifier of Min 2 (Mom2) locus, a new mutation that influences $A p c$-induced intestinal neoplasia. Genome Res. 12: 88-97.

Silverman, K.A., Koratkar, R.A., Siracusa, L.D., and Buchberg, A.M. 2003. Exclusion of Madh2, Madh4, and Madh7 as candidates for the modifier of Min 2 (Mom2) locus. Mamm. Genome 14: 119-129.

Siracusa, L.D., Silverman, K.A., Koratkar, R., Markova, M., and Buchberg, A.M. 2004. Genome wide modifier screens: How the genetics of cancer penetrance may shape the future prevention and treatment. In Oncogenomics: Molecular approaches to cancer (eds. C. Brenner and D. Duggan), pp. 255-290. John Wiley \& Sons, New York.

Song, J., Medline, A., Mason, J.B., Gallinger, S., and Kim, Y.I. 2000. Effects of dietary folate on intestinal tumorigenesis in the $A p c^{\text {Min }}$ mouse. Cancer Res. 60: 5434-5440.

Taylor, K.D. and Piko, L. 1995. Mitochondrial biogenesis in early mouse embryos: Expression of the mRNAs for subunits IV, Vb, and VIIc of cytochrome c oxidase and subunit 9 (P1) of $\mathrm{H}(+)$-ATP synthase. Mol. Reprod. Dev. 40: 29-35.

Threadgill, D.W., Hunter, K.W., and Williams, R.W. 2002. Genetic dissection of complex and quantitative traits: From fantasy to reality via a community effort. Mamm. Genome 13: 175-178.

Tucker, J.M., Davis, C., Kitchens, M.E., Bunni, M.A., Priest, D.G. Spencer, H.T., and Berger, F.G. 2002. Response to 5-fluorouraci chemotherapy is modified by dietary folic acid deficiency in $A p C^{M i n /+}$ mice. Cancer Lett. 187: 153-162.

Ulrich, S., Wolter, F., and Stein, J.M. 2005. Molecular mechanisms of the chemopreventive effects of resveratrol and its analogs in carcinogenesis. Mol. Nutr. Food Res. 49: 452-461.

Wagenaar-Miller, R.A., Hanley, G., Shattuck-Brandt, R., DuBois, R.N. Bell, R.L., Matrisian, L.M., and Morgan, D.W. 2003. Cooperative effects of matrix metalloproteinase and cyclooxygenase-2 inhibition on intestinal adenoma reduction. Br. J. Cancer 88: 1445-1452.

Warburg, O. 1956. On the origin of cancer cells. Science 123: 309-314.

Williams, R.W. 1999. A targeted screen to detect recessive mutations that have quantitative effects. Mamm. Genome 10: 734-738.

Wilson, C.L., Heppner, K.J., Labosky, P.A., Hogan, B.L., and Matrisian, L.M. 1997. Intestinal tumorigenesis is suppressed in mice lacking the metalloproteinase matrilysin. Proc. Natl. Acad. Sci. 94: 1402-1407.

Yotov, W.V. and St-Arnaud, R. 1993. Cloning and functional expression analysis of the $\alpha$ subunit of mouse ATP synthase. Biochem. Biophys. Res. Commun. 191: $142-148$.

Zheng, J. and Ramirez, V.D. 2000. Inhibition of mitochondrial proton $\mathrm{F}_{0} \mathrm{~F}_{1}$-ATPase/ATP synthase by polyphenolic phytochemicals. Br. I. Pharmacol. 130: 1115-1123.

Ziegler, C.C., Rainwater, L., Whelan, J., and McEntee, M.F. 2004. Dietary resveratrol does not affect intestinal tumorigenesis in $\mathrm{Apc}^{\mathrm{Min} /+}$ mice. J. Nutr. 134: 5-10.

Received November 1, 2006; accepted in revised form February 6, 2007. 


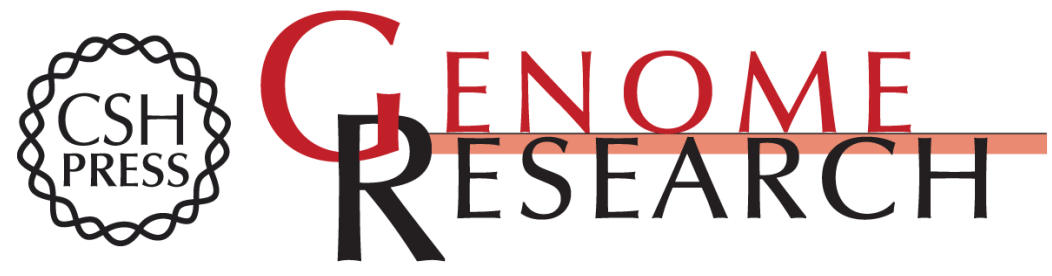

\section{The modifier of Min 2 (Mom2) locus: Embryonic lethality of a mutation in the Atp5a1 gene suggests a novel mechanism of polyp suppression}

Amy A. Baran, Karen A. Silverman, Joseph Zeskand, et al.

Genome Res. 2007 17: 566-576 originally published online March 26, 2007

Access the most recent version at doi:10.1101/gr.6089707

Supplemental http://genome.cshlp.org/content/suppl/2007/04/03/gr.6089707.DC1
Material

References This article cites 59 articles, 24 of which can be accessed free at:

http://genome.cshlp.org/content/17/5/566.full.html\#ref-list-1

\section{License}

Email Alerting Receive free email alerts when new articles cite this article - sign up in the box at the Service top right corner of the article or click here.

\section{Affordable, Accurate Sequencing.}

